\title{
Discrimination and Children's Nutritional Status in India
}

\author{
Sukhadeo Thorat and Nidhi Sadana
}

\begin{abstract}
This article explores the differing health status of lower caste social groups in India, analyses the reasons for the differences and discusses some of the implications for policy. National Family Planning and Health Survey (NFH-3) data shows that children belonging to lower castes have worse nutrition, health and mortality indicators and poorer access to health services and nutrition schemes than children from higher castes, even after other socioeconomic factors are considered. The article suggests that this points towards the possible role of discrimination and exclusion associated with caste and 'untouchability' and outlines some policy recommendations that are proactively inclusive, specifically in the nutrition domain.
\end{abstract}

\section{Introduction}

Indian society is characterised by significant differences in health status between social groups. Children belonging to lower caste social groups such as former 'untouchables' (scheduled castes) and scheduled tribes have worse nutrition, health and mortality indicators and poorer access to health and nutrition schemes compared with children from higher castes, even after controlling for other socioeconomic factors.

In this article, we use National Family Planning and Health Survey (NFHS-3) (IIPS 2005-06) data, supplemented by data from studies to describe some differences, explore the reasons for the differences, and discuss some of the implications for policy to improve access for these excluded children to health services and food security schemes.

\section{The status of scheduled castes and scheduled tribes \\ 2.1 Mortality}

Table 1 shows the disparity in child mortality rates between scheduled castes (SC), scheduled tribes (ST), other backward castes (OBC) and others (non-SC/ST/OBC) in Indian society in 2005-06. These excluded children have mortality rates that are 33-100 per cent higher than children in the rest of Indian society.

\subsection{Morbidity and undernutrition}

Table 2 shows that diarrhoea prevalence is highest for the OBC group and anaemia is 10-20 per cent higher in the excluded children compared with the rest. Iron and vitamin supplementation rates are lower too. Severe (below 3SD) underweight rates are approximately 50-100 per cent higher in the SC/ST group than the non-excluded groups and moderate (below 2SD) underweight (low weight for age) rates are approximately 50 per cent higher in the SC/ST group than the nonexcluded groups.

\subsection{Access to health services}

The above analysis brings out the poor situation of the SC and ST with respect to indicators of health and nutrition. Do the children who need health services the most, have equal use of them? Table 3 reveals that $\mathrm{SC}$ mothers and their children also suffer from relatively poor use of public health services. Access to non-AWG services is worse for the excluded children than the rest, with 20-50 per cent higher immunisation for the nonexcluded children. Perhaps surprisingly, given the label of excluded use of AWG services is higher for the SC/ST/OBC children and mothers. Given the low quality of service documented elsewhere in this IDS Bulletin, this is likely to reflect not exclusion from ICDS but from high quality child development services. 
Table 1 Health status indicator for children

\begin{tabular}{llllll}
\hline Health status indicators & Scheduled caste & $\begin{array}{c}\text { Excluded } \\
\text { Scheduled tribe }\end{array}$ & $\begin{array}{l}\text { Others (non- } \\
\text { Other backward } \\
\text { caste }\end{array}$ & All \\
\hline Infant mortality rate (IMR) & 66.4 & 62.1 & 56.6 & 48.9 & 57.0 \\
Neonatal mortality & 46.3 & 39.9 & 38.3 & 34.5 & 39.0 \\
Post-neonatal mortality rates & 20.1 & 22.3 & 18.3 & 14.5 & 18.0 \\
Child mortality rate & 23.2 & 35.8 & 17.3 & 10.8 & 18.4 \\
Under five mortality rate & 88.1 & 95.7 & 72.8 & 59.2 & 74.3 \\
\hline Source NFHS-3 (IIPS 2005-06). & & & & \\
\hline
\end{tabular}

Are these outcomes driven by the low poverty and education levels of SC/ST/OBC groups or is it discrimination, i.e. just because the families are SC/ST/OBC? To explore this, Tables 4 and 5 describe underweight outcomes (percentage of infants by standard of living, cross referencing with caste group. Tables 4 and 5 show that even when stratifying by standard of living (Table 4) and education (Table 5), SC children still have higher levels of undernutrition. This strongly points towards the possible role of discrimination associated with caste and 'untouchability'.

\section{Caste discrimination and exclusion as a factor in access}

The descriptive analysis above brings out two important social features of health status and malnourishment. It shows that for all indicators of health status, the situation of the SC and ST is much worse than other groups. The results also showed that even for individuals with a similar standard of living and education level, the health status of SC and ST is lower than their higher caste counterparts. This indicates that in addition to their poverty and education levels SCs suffer from unequal access to public services, presumably because of caste and untouchability related discrimination and exclusion.

Several studies point to discriminatory access by SC patients to public health services and schemes related to food security of school children. A study conducted by Sangamitra (forthcoming 2009) for the Indian Institute of Dalit (SC) Study and UNICEF in Gujarat and Rajasthan identifies the forms and nature of discrimination that $\mathrm{SC}$ women and children face in accessing public health services. Developing an index on a 1-5 scale for the degree of discrimination, she found that the highest degree of discrimination was reported in the dispensing of medicine, followed by diagnostic visits to the doctor (in Rajasthan) and the conduct of pathological tests (Gujarat). There was a general perception that public sector healthcare personnel discriminate more than

Table 2 Morbidity and malnutrition

\begin{tabular}{|c|c|c|c|c|}
\hline Indicators & Scheduled caste & Scheduled tribe & $\begin{array}{l}\text { Other backward } \\
\text { caste }\end{array}$ & Others \\
\hline Prevalence of diarrhoea (\%) & 8.7 & 8.8 & 9.5 & 8.6 \\
\hline Percentage of children with any anaemia & 72.2 & 76.8 & 70.3 & 63.8 \\
\hline Percentage given iron supplements in last 7 days & 3.3 & 4.3 & 4.7 & 5.6 \\
\hline Percentage given vit. A supplements in last 6 months & 18.1 & 14.8 & 17.1 & 20.9 \\
\hline \multicolumn{5}{|l|}{ Weight for age (\%) } \\
\hline Below 3SD & 18.5 & 24.9 & 15.7 & 11.1 \\
\hline Below 2SD & 47.9 & 54.5 & 43.2 & 33.7 \\
\hline
\end{tabular}

Source NFHS-3 (IIPS 2005-06). 
Table 3 Access to essential health services across social groups

\begin{tabular}{|c|c|c|c|c|}
\hline Access to essential health services & $\begin{array}{l}\text { Scheduled } \\
\text { caste }\end{array}$ & $\begin{array}{l}\text { Scheduled } \\
\text { tribe }\end{array}$ & $\begin{array}{l}\text { Other } \\
\text { backward } \\
\text { caste }\end{array}$ & Others \\
\hline Treatment of diarrhoea from health facilities (\%) & 60.7 & 54.3 & 57.5 & 64.9 \\
\hline Knowledge of ORS packets & 71.4 & 61.4 & 70.8 & 79.4 \\
\hline Percentage who received oral rehydration therapy for diarrhoea & 37.7 & 46.3 & 41.4 & 48.3 \\
\hline Percentage of children vaccinated & 39.7 & 31.3 & 40.7 & 53.8 \\
\hline Children aged 0-71 months receiving any services from AWC (\%) & 36.1 & 49.9 & 30.3 & 28.3 \\
\hline $\begin{array}{l}\text { Children aged } 0-71 \text { months who received supplementary food } \\
\text { from an AWC (\%) }\end{array}$ & 30.4 & 43.9 & 22.4 & 23.2 \\
\hline $\begin{array}{l}\text { Children aged } 0-71 \text { months who received any immunisation } \\
\text { services from an } A W C(\%)\end{array}$ & 21.4 & 33.1 & 20.5 & 13.3 \\
\hline $\begin{array}{l}\text { Frequency of going to an AWC regularly for early childhood } \\
\text { care/pre-school education for children aged } 36-71 \text { months }\end{array}$ & 15.8 & 16.0 & 12.9 & 13.4 \\
\hline $\begin{array}{l}\text { \% distribution of children aged 0-59 months covered by AWC } \\
\text { by frequency of weighing }\end{array}$ & 78.1 & 64.2 & 83.3 & 82.7 \\
\hline
\end{tabular}

Source NFHS-3 (IIPS 2005-06).

\begin{tabular}{lcc}
\hline \multicolumn{3}{l}{ Table 4 Nutritional status by standard of living index across social groups } \\
\hline \multicolumn{3}{c}{ Underweight (\%) } \\
Standard of living index & Scheduled caste & Others \\
\hline Low & 57.2 & 46.9 \\
Medium & 44.7 & 41.7 \\
High & 33.0 & 24.6 \\
Total & 47.8 & 33.7 \\
\hline
\end{tabular}

Source NFHS-3 (IIPS 2005-06).

Table 5 Nutritional status by educational level of mother across social groups

\begin{tabular}{lll}
\hline \multirow{2}{*}{ Education } & \multicolumn{2}{c}{ Underweight (\%) } \\
\hline Illiterate & Scheduled caste & Others (non-SC/ST/OBC) \\
Primary & 54.2 & 45.7 \\
Secondary & 43.6 & 36.2 \\
Higher & 38.5 & 27.7 \\
Total & 18.2 & 14.9 \\
\hline
\end{tabular}

Source NFHS-3 (IIPS 2005-06). 
private healthcare personnel. Access to information is an area of discrimination where Dalits do not receive the information needed to inform their health seeking behaviour and health status. Health personnel discriminate by not visiting SC habitations and families. When they do visit, they express discomfort and disrespect for their patients. The study reported that most healthcare camps are held in dominant caste locations reducing access by Dalit communities. Responses from the SC children indicate that they would like the healthcare provider to speak gently, using respectful words, treating them as equals, spending adequate time and treating them based on the severity of the illness.

Another study conducted by the Indian Institute of Dalit Studies in about 550 villages from five states, on the midday meal scheme, which provides meals to children in nursery and primary school reported exclusion and discriminatory treatment. Discrimination in the midday meal included: the denial of meals; separate seating for SC children; serving SC children last; SC children being punished for asking to be served first; not being served a sufficient quantity or quality; serving from a distance; and the most widespread and prominent discrimination found - the refusal to employ SC cooks.

ActionAid conducted a very comprehensive survey of caste discrimination and 'untouchability' in 555 villages in 11 states (ActionAid 2000) which found that caste discrimination was widespread across rural India and that SCis were effectively but informally excluded from many domains of social and economic life. In 47 per cent of the villages surveyed, for example, SGs were unable to sell their milk to cooperatives or private buyers because it was believed to be polluted. The National Family Household Survey results described above provide evidence that public health and nutrition services are not immune or isolated from wider informal beliefs, and practices that permeate every other sphere of life. Physical contact (touch) and ingestion are believed to be two key modes for the transmission of 'impurity' and 'pollution'. Given that health provision involves physical contact and that nutrition involves ingestion, it is not altogether surprising that front-line workers hold these views and practice avoidance. What is more surprising is that science has not been used to actively counter these beliefs in the routine training of modern health workers.

\section{Conclusion: the need for proactively inclusive policies and processes}

The description of health status and undernutrition revealed that for nearly all health indicators, the situation of the SC and ST children is worse than other groups. This is related to low income and poor education, but also low access to public health services supplied by government institutions. Even for individuals with a similar standard of living and education level, the health status of SC and ST children is lower than their counterparts from higher castes. This requires general policies to promote equity, but also proactive measures to address the problems of the social groups that are discriminated against. More emphasis on antipoverty and education programmes, and a massive awareness programme for rural people would certainly help all, including the SC and ST, to improve their health and access healthcare services from public health institutions. But additional policy measures are needed to overcome the obstacles imposed by caste and untouchability based discrimination.

There is hope, because 'untouchability' is not an insurmountable barrier to access all provision. The National Family Household Survey (2005-06) reveals that SC/ST women are more likely than women from any other group to access surgical methods of family planning. This suggests that health service providers can and do reach out to SC/ST clients when the incentives are right. Although it has been known and doccumented for at least 20 years that caste discrimination and notions of impurity influence providers' treatment behaviour (Schuler 1985), there are relatively few studies that focus on how to make services more inclusive. This is an area where action research is urgently needed in India. We outline below nine further recommendations to address the situation described above, specifically in the nutrition domain.

- There needs to be a national public awareness campaign on the cost that discrimination inflicts on individual children who pay with their lives and their health.

- Priority should be given to constructing new and better ICDS centres and health facilities in underserved SG and ST habitations. 
- More effforts should be made to recruit women from SC and ST communities as ICDS anganwadi workers (AWW) and auxilliary nurse midwives (ANM).

- In order to reach the educational threshold required for AWW and ANM training, greater efforts should be made to increase the numbers of girls from SC/ST communities completing basic education and making the transition to secondary and higher education.

- A representative proportion of ASHAs (community health volunteers) must be selected from SC/ST communities and unreached habitations. Data should be available on what proportion of ASHAs come from SC/ST communities.

- Non-government organisations who are subcontracted to deliver health outreach should emphasise social inclusion and preference should be given to those who recruit from underserved communities.

- ICDS and health workers should receive performance related rewards for reaching underserved SC/ST communities.

\section{References}

IIPS International Institute of Population Sciences (2005/06) National Family Health Survey, Mumbai

Sangamitra, Acharya (forthcoming 2009) 'Public Health Care Services and Caste Discrimination: A Case of Dalit Children', in S.K. Thorat (ed.), Blocked by Caste-Economic Discrimination and Social Exclusion in Modern India, New Delhi: OUP
- All health and ICDS worker training should include modules on the adverse effects of gender and caste discrimination on public health and nutrition outcomes.

- M\&E systems at District and facility level need to be disaggregated by social group and capacity must be built to analyse and use such data to identify the individuals and groups that are underserved and to identify where 'bottlenecks' within the system exist, so that corrective management action can be taken. Such data should be open to public scrutiny and SC/ST organisations should be trained to analyse and use it.

The roll out of ICDS 4 seems an excellent context within which to experiment with ways of reaching out and including SC/ST children, documented by rigorous action research.

Shah, Ghanshyam; Deshpande, Satish; Thorat, Sukhadeo; Mander, Harsh and Baviskar, Amita, for ActionAid (2000) Untouchability in Rural India, Delhi: ActionAid

Schuler, S.R.; McIntosh, E.N.; Goldstein, M.C. and Pande, B.R. (1985) 'Barriers to Effective Family Planning in Nepal', Studies in Family Planning 16.5: 260-70 